Original Research Article

\title{
Drug utilization study in the paediatric department of a tertiary care teaching hospital
}

\author{
Ananditha Sharma Kopparthy ${ }^{1}$, Sowmya Kaniganti ${ }^{2 *}$, Ravikumar Chodavarapu ${ }^{3}$
}

\author{
${ }^{1}$ Student, ${ }^{2}$ Department of \\ Pharmacology, ${ }^{3}$ Department of \\ Paediatric, Dr. Pinnamaneni \\ Sidhartha Institute of Medical \\ Sciences and Research \\ Foundation, Vijayawada, \\ Andhra Pradesh, India \\ Received: 25 May 2019 \\ Accepted: 29 May 2019 \\ *Correspondence to: \\ Dr. Sowmya Kaniganti, \\ Email: sowmya.kaniganti@ \\ gmail.com \\ Copyright: (C) the author(s), \\ publisher and licensee Medip \\ Academy. This is an open- \\ access article distributed under \\ the terms of the Creative \\ Commons Attribution Non- \\ Commercial License, which \\ permits unrestricted non- \\ commercial use, distribution, \\ and reproduction in any \\ medium, provided the original \\ work is properly cited.
}

\begin{abstract}
Background: Rational drug use is one of the main concerns of the health care system in India. Paediatric population being more vulnerable require additional focus to achieve this goal. Objectives of the study were to evaluate the prescription patterns according to WHO guidelines and the diseases, for which they are being prescribed, to identify the common diseases and common medications used.
\end{abstract}

Methods: A cross sectional study was done in the paediatrics department for a period of 2 months. All the paediatric prescriptions were evaluated using WHO core indicators like average number of medicines per encounter, percentage of medicines from the essential drug lists and also complimentary indicators like utilization of different dosage forms and diagnostic patterns. Statistical Analysis: Data was analyzed and represented as frequency (n) and percentage (\%).

Results: 89 out of 302 prescriptions had 2 medicines per encounter, $100 \%$ of medicines were included from the Essential Drug List (EDL), 59.4\% of the medicines were in generic format of prescription.

Conclusions: This study gives a positive outlook at the utilization pattern of drugs with all the indicators specifically Essential Drugs List. Regular auditing, continuous medical education and evidence-based medicine can help in improving the health care.

Keywords: Drug utilization, Paediatrics, Prescription pattern

\section{INTRODUCTION}

According to WHO, Drug utilization studies can be defined as "marketing, distribution, prescription and use of the drug in the society with special emphasis on the resulting medical, social and economic consequences. ${ }^{1}$ Rational drug use is one of the main concerns of the health care system in every country. Irrational use of antimicrobials is one of the main contributing factors for the developments of antimicrobial resistance, increased economic and health burden to the society. In order to achieve this goal, WHO promoted the concept of essential drug program and selection of essential drugs in $1997 .^{2}$ Study of prescribing practices can be considered as a reflection of the abilities of health professional to determine the choice of drug and the choice for the benefit of the patient. ${ }^{3}$ Drug utilization studies can describe the situation of drug use in individual health care facilities. They are important tools to evaluate the utilization of drugs in terms of safety, efficacy, convenience and economic aspects at all the levels in the chain of drug use. ${ }^{2}$

Various indicators have been developed by the International Network for the Rational Use of Drugs 
(INRUD) in collaboration with WHO, which help us in assessing the practices of drug use and remedial measures. ${ }^{4,5}$ These studies can critically analyze the current hospital drug policies to make recommendations based on various guidelines to improve drug usage pattern. ${ }^{6}$ The assessment of drug utilization is important for clinical, educational and economic purposes. Importance of drug utilization studies in pharmacoepidemilogy has also been increasingly associated with public health, pharmacovigilance, pharmacoeconomics and pharmacogenetics. $^{3}$ Drug utilization studies which are conducted periodically can favour the auditing and provide feedback to the prescribers, pave for critical analysis of the health policies and make recommendations. ${ }^{7}$

There are many potential difficulties involved with prescribing to children especially the pharmacokinetic changes which make them categorize under the vulnerable population. Infections which depend on many factors are one of the largest causes of morbidity and mortality worldwide. The recognition of drug toxicity following inappropriate drug selection and dosing predominantly in paediatric patients is exceedingly important. ${ }^{8}$ Thoughtful drug therapy strategies need to be established for the safe and effective use of drugs in sick neonates, infants, children and adolescents. $^{7}$

This study was undertaken to evaluate the prescription patterns according to WHO guidelines and the diseases, for which they are being prescribed, to identify the common diseases and common medications used.

\section{METHODS}

A cross sectional drug utilization study was carried out in the paediatric department of Dr. Pinnamaneni Sidhartha Institute of Medical Sciences and Research Foundation, Chinnavutapally as a part of STS (Short Term Studentship) ICMR approved project 2017. The study was conducted after obtaining the approval of Institutional Ethical Committee (IEC). Informed consent of the parent/guardian was obtained. Confidentiality of the patient and the prescriber was maintained. All the prescriptions of the paediatric patients (newborn to $14 \mathrm{yrs}$ ) in the outpatient, inpatient and critical care departments were included in the study.

Study period was from July 2017 to August 2017, 2 months.

The various prescription indicators recommended by WHO $(2,10)$ used in the study were:

- Average number of medicines per encounter.

- Percentage of medicines prescribed from essential drug list.

- $\quad$ Percentage of medicines prescribed by generic name.

- Percentage of encounters with an antibiotic prescribed.
- Percentage of encounters with an injection prescribed.

Apart from the prescribing indicators other complimentary indicators also were analyzed and were:

- Top ten category of medicines.

- Diagnostic characteristics of the patients.

- Utilization of different dosage forms.

\section{Statistical analysis}

Data was analyzed and represented as frequency (n) and percentage $(\%)$.

\section{RESULTS}

Table 1 describes the sex distribution and age distribution among the study population (302). The demographics of the prescriptions of the patients which were analyzed include 157 males and 145 females. The maximum numbers of prescription analyzed (41.72) were in the age group (1-6yrs). $24.83 \%$ of the prescriptions were prescribed to the neonates $(4.3 \%)$.

Table 1: Pediatric patient related parameters.

\begin{tabular}{|lll|}
\hline Parameter & Number of patients & $(\%)$ \\
\hline & Sex & \\
\hline Males & 157 & 51.9 \\
\hline Females & 145 & 48.1 \\
\hline & Age & \\
\hline Neonate (upto 4wks) & 13 & 4.30 \\
\hline Infants (4wks-1yr) & 88 & 29.13 \\
\hline Children (6-14yrs) & 75 & 24.83 \\
\hline
\end{tabular}

Table 2 depicts the number of medicines per prescription. The prescriptions were analyzed for the total number of medicines in each prescription and belonging to any category. About 89 prescriptions included only 2 medicines whereas only 2 prescriptions included 9 medicines. About $15.2 \%$ of the prescriptions analysed contained 4 medicines per prescription.

Table 2: Number of medicines per prescription.

\begin{tabular}{|lll|}
\hline $\begin{array}{l}\text { Drugs per } \\
\text { prescription }\end{array}$ & $\begin{array}{l}\text { Number of } \\
\text { prescriptions }\end{array}$ & $\begin{array}{l}\text { Percentage } \\
(\%)\end{array}$ \\
\hline 1 & 71 & 23.5 \\
\hline 2 & 89 & 29.4 \\
\hline 3 & 76 & 25.1 \\
\hline 4 & 46 & 15.2 \\
\hline 5 & 16 & 5.2 \\
\hline 6 & 2 & 0.62 \\
\hline 9 & 2 & 0.62 \\
\hline
\end{tabular}

Table 3 evaluates the percentage distribution of medicines that were prescribed from essential drug list (EDL), 
containing generic names and injections. Among 781 medicines that were prescribed from 302 prescriptions, 464 included generic names, 67 were injections and all the medicines $(100 \%)$ were from the essential drug list.

Table 4 describes the diagnostic pattern of the diseases among the study population. The table represents the frequency of the diseases among neonates, infants, children (1-6yrs and 7-14 yrs). About 33 children (1-6yrs) were diagnosed with respiratory tract infections (URTI and LRTI). The most common disease among all the age groups was a combination of fever with either jaundice, diarrhea or cold and cough (32.3\%).

Table 3: Percentage of medicines prescribed (generic name and EDL).

\begin{tabular}{|llll|}
\hline & Total number of medicines prescribed & Frequency $(\mathbf{N})$ & $(\%)$ \\
\hline Generic drugs & 781 & 464 & 59.4 \\
\hline Prescribed from essential drug list(edl) & 781 & 781 & 100 \\
\hline Injections & 781 & 67 & 8.5 \\
\hline
\end{tabular}

(EDL-Essential Drug List)

Table 4: Diagnosis pattern in different age groups.

\begin{tabular}{|c|c|c|c|c|c|}
\hline \multirow[t]{2}{*}{ Diagnosis } & \multicolumn{4}{|c|}{ Frequency(n) } & \multirow[b]{2}{*}{ Total } \\
\hline & Neonates & Infants & Children (1-6yrs) & Children(7-14yrs) & \\
\hline URTI and LRTI & 5 & 21 & 33 & 7 & $66(22.4 \%)$ \\
\hline Gastroenteritis & 7 & 21 & 25 & 8 & $61(20.7 \%)$ \\
\hline Seizures & 0 & 2 & 4 & 7 & $13(4.4 \%)$ \\
\hline Asthma & 0 & 4 & 11 & 5 & $20(6.8 \%)$ \\
\hline Undiagnosed & 2 & 6 & 5 & 2 & $15(5.1 \%)$ \\
\hline Others & 3 & 2 & 11 & 8 & $24(8.2 \%)$ \\
\hline Combination & 1 & 17 & 33 & 40 & $95(32.3 \%)$ \\
\hline
\end{tabular}

(URTI- upper respiratory tract infection, LRTI- lower respiratory tract infection, others- snake bite, neurocysticercosis, acute pancreatitis, hypothyroidism, Combination- fever with jaundice, fever with cold and cough, fever with diarrhoea and vomiting.

Figure 1 represents the percentage of antimicrobials prescribed. About $34.5 \%$ of medicines were in the category of pencillins, $16 \%$ belonged to the macrolide group and $1 \%$ of medicines from other than aminoglycosides, pencillins, cephalsporins, macrolides.

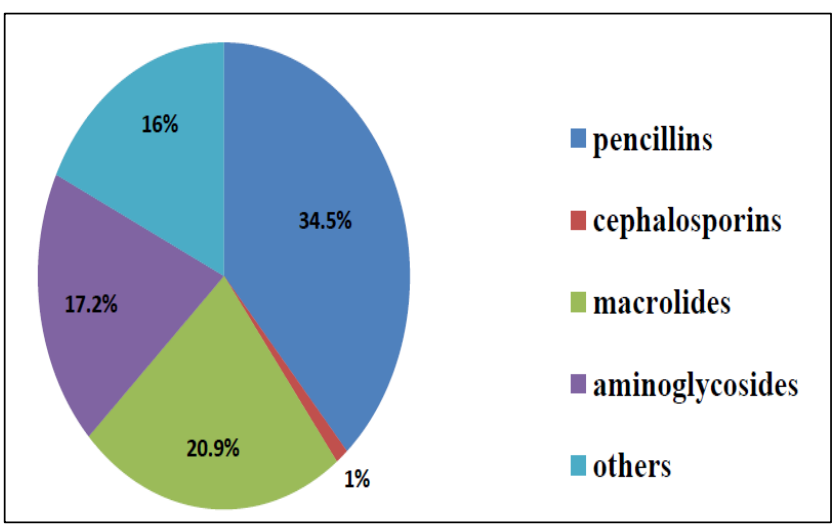

Figure 1: Percentage of antimicrobials prescribed.

Figure 2 shows the medicines prescribed from various classes including the antimicrobials. About $48 \%$ of the medicines belonged to NSAIDS (Non-steroidal antiinflammatory drugs) category. Only $3 \%$ of the 302 prescriptions analysed and 781 medicines prescribed belonged to the antimicrobial category.

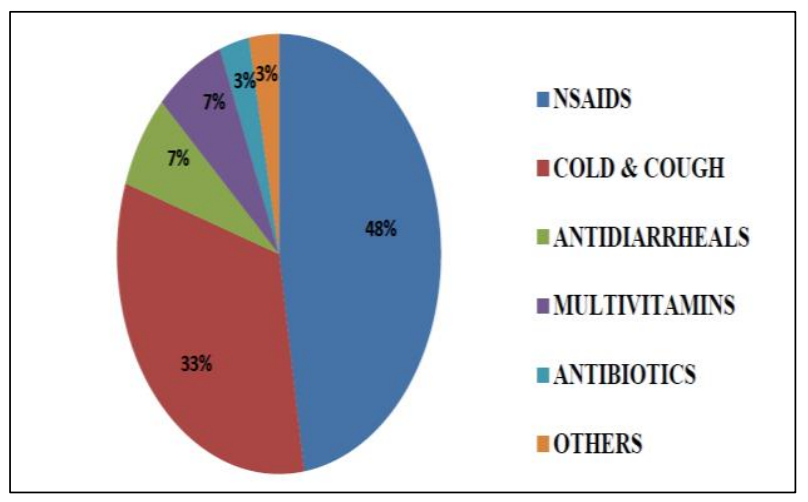

Figure 2: Drugs prescribed from various classes.

Figure 3 represents the distribution of various routes of drug administration. Highest percentages of medicines $(74.5 \%)$ were prescribed by oral route, $33.4 \%$ by topical route and $9.6 \%$ of the medicines prescribed were of parenteral route. The distribution contained oral, parenteral, topical and inhalational routes of drug delivery.

Figure 4 shows the various dosage forms prescribed in the study. 173 of the medicines prescribed were in syrup form, 
5 prescriptions included inhaler or nebulisation, 81 medicines were prescribed in tablet form, 72 medicines prescribed in the form of nasal/ear drops.

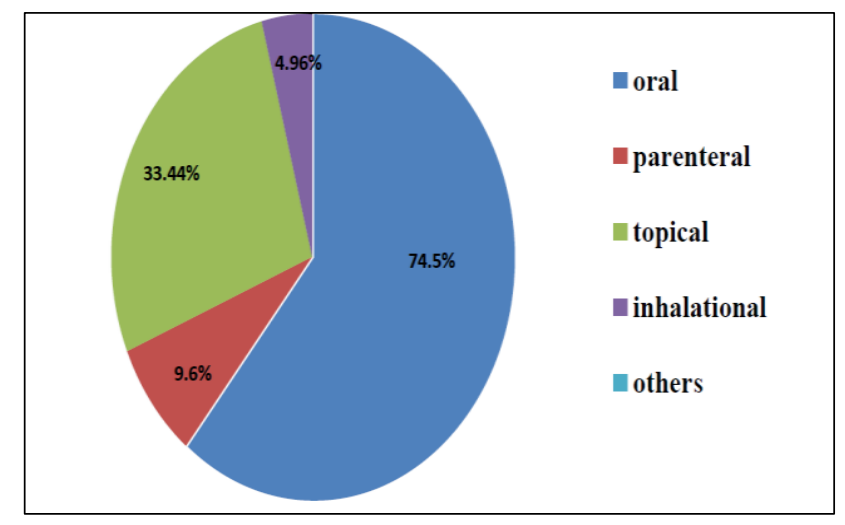

Figure 3: Distribution of routes of drug administration.

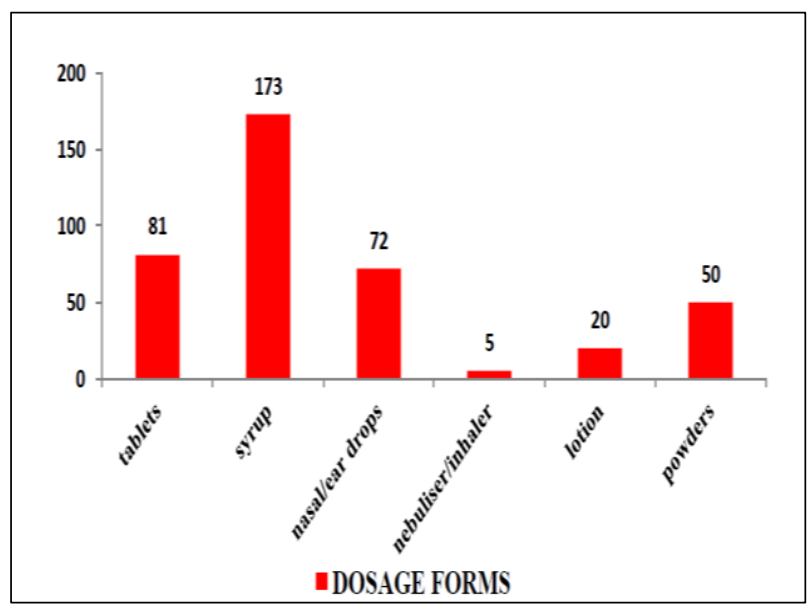

Figure 4: Various dosage forms prescribed.

\section{DISCUSSION}

Drug utilization studies includes the description of drug usage pattern, early signals of irrational drug use, interventions to improve drug usage and also quality control of drug use. Studies done on a large scale can aid in recognition of the adverse effects in concordance with Pharmacovigilance. The links in DUS include systems and structures, process of drug use and outcomes of drug use.

This study focused in the process of drug use in relation to the WHO prescribed indicators and core indicators. As compared to other studies. ${ }^{2,9}$ Present study also showed male preponderance in the study population (Table 1). From (Table 2), the maximum number of prescriptions (29.4\%) included only 2 medicines and only $5 \%$ of prescriptions included 5 medicines. The average number of medicines per encounter was 2.58. This was comparable to the study done by Kumar AM et al. ${ }^{2}$ This is considered as acceptable by WHO and also indicates that polypharmacy is not a major concern in hospital. As per Medical Council of India (MCI), all the prescriptions should include generic names. It is also known to reduce the cost of drug treatment and rationalizing drug therapy. In this study about $59.4 \%$ of the prescriptions included generic names. These results were diverse compared to the study done by Akhtar MS where only $2.63 \%$ of drugs were prescribed by generic name. $^{4}$

From (Table 3), 100\% of medicines were included from the Essential Drug List (EDL) recommended by WHO. This indicates the knowledge and awareness of the prescriber regarding the EDL and also motivate the young doctors to adhere to the guidelines. Only about $8.5 \%$ of the medicines included injections. From (Table 4), about $22.4 \%$ of the study population were diagnosed with URTI and LRTI. $32.3 \%$ were diagnosed with a combination of fever with cold and cough, fever with jaundice, fever with diarrhea. This gives us a comprehensive view about the pattern and will enable us to train the future prescribers about the common diseases.

From (Figure 1), it was evident that about $34.5 \%$ pencillins, $20.9 \%$ macrolides, $16 \%$ included drugs like antifungals, antihelminthics, cotrimoxazole. This study can aid in keeping a check on the irrationality and also encourage the faculty in the department to maintain uniformity. From (Figure 2), 48\% of the medicines included NSAIDS like paracetamol, $33 \%$ cold and cough medications. The top ten category of medicines prescribed in present study included paracetamol, nasal drops, salbutamol, montelukast, ORS, vitamin D3, pencillins, cephalosporins, azithromycin and amikacin. Only $3 \%$ of 781 medicines prescribed included antibiotics. Irrational use of antibiotics was not observed in our study. This indicates that the antibiotic policy was adhered to by all the prescribers in the paediatric department. These results were different to the observations in the study done by Thiruthopu NS et al. ${ }^{5}$

From (Figure 3), it was observed that $74.5 \%$ of the medicines prescribed were by oral route, $9.6 \%$ of medicines prescribed by parenteral route. This can also be attributed to the fact that the outpatient population was higher than the inpatient or the critical care patients during the study period. From (Figure 4), 173 out of 781 medicines were in syrup dosage form, $81 \%$ as tablets, $50 \%$ as powders. These results were similar to the study done by Kumar AM. ${ }^{2}$

Limitations of the study were that the study only focused on the prescription indicators. Facility indicators and patient care indicators were not taken into consideration. Pharmacoeconomic evaluation of the medicines was not done. Seasonal variations in the disease pattern were not considered. The study was restricted to only one hospital.

\section{CONCLUSION}

Drug utilization studies are important tools to highlight the prescribing trends in the hospital and drugs prescribed from the EDL will give a positive outlook to the prescribers and 
the patient outcome. This study gives a positive outlook at the utilization pattern of drugs with all the indicators specifically Essential Drugs List, minimal use of antimicrobials and generic prescriptions. The assessment of WHO core indicators and complementary indicators can help us decrease the cost burden on the patient. Continuous medical education with particular focus on rational drug usage and evidence based medicine can further increase the understanding. Regular clinical auditing can also help in improving the health care policies by the regulatory authorities. The prescribers can let go of the inertia and hesitance to conduct these studies and contribute to the societal well being.

Funding: No funding sources Conflict of interest: None declared

Ethical approval: The study was approved by the Institutional Ethics Committee

\section{REFERENCES}

1. World Health Organization (WHO). Introduction to drug utilization research 2003 Chapter 1 [internet]. Geneva: WHO; 2003. Available at: www.https://apps.who.int/medicinedocs/en/d/Js4876e /

2. Kumar AM, Ram TK, Ramaswamy C. Cross-sectional prospective study on drug utilization in an outpatient pediatric department of tertiary care teaching hospital. Global J Pharmacol. 2013;7(2):99-103.

3. Venkateswaramurthy N, Murali R, Kuamr SR. The study of drug utilization pattern in pediatric patients. Int J Pharm Pharmaceu Sci. 2013;5(3):140-4.

4. Akhtar MS, Divya V, Pillai KK, Kiran D, Roy MS, Najmi AK et al. Drug prescribing practices in pediatric department of a north Indian university teaching hospital. Asian J Pharma Clinical Res. 2012;5(1):14649.

5. Thiruthopu Swamy N, Uday VM, Raju B, Divya S, Srinivas M. Drug utilization pattern in south Indian pediatric population a prospective study. Perspective Clinical Res. 2014;5(4):178-83.

6. Sharonjeet K, Sujit R, Navjot K, Nusrat S, Asish B, Promila $\mathrm{P}$ et al. Drug utilization study in medical emergency unit of a tertiary care hospital in north India. Emergency Medicine Int. 2014:1-5.

7. Neeta CS, Shailender S. Study of drug utilization in intensive care management of neoantes at tertiary care hospital. Int J Basic Clin Pharmacol. 2017;6(6):15304.

8. Susan LT, Lavanya S, Sudaroli M, George PK. Prescribing patterns of drugs in outpatient department of pediatrics in tertiary care hospital. Ind J Pharmacy Practice. 2014;7(4):16-19.

9. Nakul G, Safhi M, Jameel MYS, Meetu A. Drug prescribing patterns in children registered in the department of pediatrics of Jizan general hospital of Jizan KSA. Int J Pharmacy Pharm Sci. 2013;5(4):3979.

10. Najmi A, Verma A, Aiman U. Drug utilization study in the outpatient pediatric department of a tertiary care teaching hospital of district Lucknow. Asian J Pharmceu Cli Res. 2015;8(3):327-30.

Cite this article as: Kopparthy AS, Kaniganti S, Chodavarapu R. Drug utilization study in the paediatric department of a tertiary care teaching hospital. Int J Basic Clin Pharmacol 2019;8:1518-22. 